Sharif University of Technology
Scientia Iranica
Transactions A: Civil Engineering
SCIENTIA
IRAN I CA

\title{
An integrated fuzzy multi-criteria group decision making approach for project delivery system selection
}

\author{
M. Khanzadi ${ }^{a}$, F. Nasirzadeh ${ }^{\mathrm{b}, *}$, S.M. Hossein Hassani ${ }^{\mathrm{a}}$ and \\ N. Nejad Mohtashemi ${ }^{\mathrm{c}}$ \\ a. Department of Civil Engineering, Iran University of Science and Technology, Tehran, Iran. \\ b. Department of Civil Engineering, Faculty of Engineering, Payame Noor University (PNU), Tehran, P. O. Box 19395-4697, Iran. \\ c. Department of Construction Engineering and Management, Science and Research Branch, Islamic Azad University, Tehran, Iran.
}

Received 16 September 2014; received in revised form 6 July 2015; accepted 11 January 2016

KEYWORDS
Project delivery
system;
AHP;
Fuzzy logic;
Multi-criteria group
decision making;
Construction projects.

\section{Introduction}

The increasing complexity and uncertainty of construction projects have led to many significant losses for the construction industry [1]. Construction industry, as a whole, suffers from low profit margin, persistent project overruns in schedule and budget, and is plagued with claims and counter-claims [2]. Adoption of a suitable Project Delivery System (PDS) plays an important role to avoid such major problems. In fact, the suitability of the Project Delivery System (PDS) selected for a project greatly influences the efficiency to conduct a project [3]. The right system may help avoid

*. Corresponding author.

E-mail addresses: khanzadi@iust.ac.ir (M. Khanzadi);

f.nasirzadeh@gmail.com (F. Nasirzadeh);

smh.hassani@gmail.com (S.M. Hossein Hassani);

negar_mohtashemi@yahoo.com (N. Nejad Mohtashemi) problems and be the key to attainment of projectspecific goals [4].

Project delivery system is defined as a contractual arrangement by which the design, construction, and procurement portions of work are assigned to the parties involved in a project [5]. Some research has been conducted to deal with the PDS selection problem. Early research on PDS selection problem has led to interpretive and descriptive models. Gordon [6] presented a qualitative model to choose appropriate contracting method based on the compatibility of various contracting methods with certain types of owners, projects, and market drivers.

In the recent years, however, a number of systematic decision making methods have been applied for the PDS selection problem. In most of the research, a Multi-Criteria Decision Making (MCDM) tool is implemented to select the most appropriate PDS. Alhazmi and McCaffer [7] presented a project 
procurement system selection model that integrates the Analytic Hierarchy Process (AHP) and Parker's judging alternative technique of value engineering into a multi-criteria multi-screening system. Cheung et al. [8] developed an objective-subjective procurement selection approach considering the subjective nature of PDS selection problem. In this research, the decision makers were allowed to assign weights against a set of selection criteria. The objectivity and reliability of these subjective elements were enhanced through the use of AHP. Mahdi and Alreshaid [9] also used AHP method in selecting an appropriate project delivery system. Oyetunji and Anderson [10] proposed a method with generating quantitative relative effectiveness values and applying these values to the Simple Multi Attribute Rating Technique (SMART) method to select an appropriate project delivery system. Mafakheri et al. [11] presented a multi-criteria multi-level decision aid model by integrating interval AHP and rough approximation to address uncertainties inherited in PDS problem. Mostafavi and Karamouz [12] developed a Fuzzy Multi Attribute Decision Making (FMADM) model in which project delivery system alternatives were ranked using fuzzy Technique for Order Preference by Similarity to Ideal Solution (TOPSIS) method. The risk attitude of the decision maker was also considered in the model. Chen et al. [3] proposed an ANN based model to select the most suitable PDS for the Chinese construction projects. The model uses a large database of Chinese projects and selects similar projects to the target one considering the main indicators and predicts the suitable PDS for the target project.

The previous research, however, faced one or a combination of the following defects. In most of the previous research, a single Decision Maker (DM) has been used to choose the optimum PDS. Although there were a few works that employed different DMs, none of them accounted for the relative importance of DMs. However, since different DMs have different levels of knowledge and experience, we are faced with a heterogeneous group of experts and the relative importance of DMs should be taken into account. Moreover, the uncertainties inherited in PDS selection problem are not completely taken into account in the previous works. In the early stages of project development, most of the parameters considered in the PDS selection are indefinite and vaguely defined. These uncertainties also arise from the subjective nature of the opinions of experts. There exists only one previous work in which the uncertainties in the scores given to criteria are accounted, while the uncertainties in the relative weights of criteria are ignored. Lastly, the previous works have not the capability to aggregate different opinions given by a group of experts.

This research presents an integrated fuzzy-AHP multi-criteria group decision making (FMCGDM) approach for PDS selection problem. The proposed approach resolves the abovementioned shortcomings. The proposed FMCGDM approach can select the best PDS option based on the opinions of a heterogeneous group of experts. The relative weights of different criteria as well as their scores are evaluated using AHP technique. The crisp values of criteria weights and scores assigned by different DMs are aggregated and converted to a fuzzy number. For this purpose, the triangular fuzzy numbers of criteria weights and scores are constructed. The relative weights of decision makers are determined using a new method based on the diversity of opinions given by a group of experts and the opinion of the group manager. In order to determine the final fuzzy score of each PDS option, the fuzzy numbers of relative weights of criteria and their assigned scores are multiplied and summed up for each PDS option using Zadeh's extension principle [13] and performing interval arithmetic at discrete $\alpha$-cuts. Finally, the fuzzy score of each PDS option is defuzzified and the best alternative PDS is selected. Sensitivity analysis is conducted on the achieved final results in order to assure their validity. To evaluate the applicability and performance of the proposed fuzzyAHP group multi-criteria decision making method, it is implemented on a real-world dam and hydro power plant project.

\section{Fuzzy-AHP group multi-criteria decision making methodology}

\subsection{Analytic Hierarchy Process (AHP)}

The Analytic Hierarchy Process (AHP), introduced by Saaty [14], is a basic approach to decision making. The AHP technique performs pairwise comparisons to measure the relative importance of elements at each level of the hierarchy and evaluates alternatives at the lowest level of the hierarchy in order to make the best decision among multiple alternatives. AHP provides decision makers with a way to transform subjective judgments into objective measures. Results of a comprehensive study conducted by Sipahi and Timor shows that the use of the AHP technique has continued to increase, exponentially. They also showed that applications of AHP have been varied from manufacturing to environmental management and agriculture fields, power and energy industry, transportation industry, construction industry, and healthcare [15].

The main advantages of using the AHP methodology are: (1) The hierarchical structure definition permits understanding of all the variables involved and their relationship; (2) The decisional problem is represented in a structured way; (3) The method does not replace the personnel involved in the resolution process, but integrates all the judgments with structured 
Table 1. Analytic hierarchy process comparison scale.

\begin{tabular}{cc}
\hline Weight & Definition \\
\hline 1 & Equal importance \\
3 & Weak importance of one over another \\
5 & Essential or strong importance \\
7 & Very strong importance \\
9 & Absolute importance \\
$2,4,6,8$ & Intermediate values between the two \\
\hline
\end{tabular}

links; and (4) from simple choice, the decision becomes process [16].

In this method, the decision maker carries out simple pairwise comparison judgments which are then used to develop overall priorities for ranking the alternatives. The AHP allows for inconsistency in judgments and provides a method to improve consistency. AHP consists of three parts including the hierarchy structure, the pairwise comparisons matrix, and the priorities calculations. A hierarchy consists of three levels: the goal of the decision at the top level, followed by a second level, consisting of the criteria by which problem alternatives, located in the third level, will be evaluated [17]. The pairwise comparison is based on a scale of 1-9, as shown in Table 1 [18]. The composition of these judgments determines the relative priority of the alternatives [19].

Assume that we have " $n$ " objects denoted by $Q_{1}, Q_{2}, \ldots, Q_{n}$ with the weights of $w_{1}, w_{2}, \ldots, w_{n}$, respectively. The pairwise comparisons can be shown in the form of a matrix $[\mathrm{G}]$ as follows:

$$
\begin{aligned}
{[G]=} & {\left[\begin{array}{cccc}
g_{11} & g_{12} & \ldots & g_{1 n} \\
g_{21} & g_{22} & \ldots & g_{2 n} \\
\vdots & \vdots & \ddots & \vdots \\
g_{n 1} & g_{n 2} & \ldots & g_{n n}
\end{array}\right]=} \\
& {\left[\begin{array}{cccc}
w_{1} / w_{1} & w_{1} / w_{2} & \ldots & w_{1} / w_{n} \\
w_{2} / w_{1} & w_{2} / w_{2} & \ldots & w_{2} / w_{n} \\
\vdots & \vdots & \ddots & \vdots \\
w_{n} / w_{1} & w_{n} / w_{2} & \ldots & w_{n} / w_{n}
\end{array}\right] . }
\end{aligned}
$$

For a reciprocal matrix $[G]$, we have $G \cdot W=\forall_{\max } \cdot W$ where $\forall_{\text {max }}$ denotes the largest eigenvalue of $[G]$ and the weight vector $[W]$ can be acquired by solving this eigenvalue problem as follows:

$$
\forall_{\max }^{(i)}=\sum_{j=1}^{n} g_{i j} w_{j} / w_{i}, \quad i=1,2, \ldots, n,
$$

where, by taking the average of all values of $\forall_{\max }^{i}$ obtained by Eq. (1), the overall $\forall_{\text {max }}$ is acquired.

In order to measure the reliability of judgments through the pairwise comparisons, a Consistency Index
(C.I.) is introduced as follows:

$$
\text { C.I. }=\left(\forall_{\max }-n\right) /(n-1),
$$

where, $n$ is the size of matrix. A ratio called Consistency Ratio (C.R.) is then developed to compare the C.I. value of a particular matrix with that of a matrix with the similar size:

$$
\text { C.R. = C.I./R.I., }
$$

where, R.I. is the average consistency index of a randomly generated reciprocal matrix. In the case C.R. is less than 0.1, the judgments are considered reliable. If C.R. is more than 0.1, a reassessment should be conducted [17].

\subsection{Fuzzy sets theory}

Fuzzy sets theory, introduced by Zadeh [13], is increasingly used for uncertainty assessment in situations where little deterministic data is available [20]. The use of fuzzy sets theory allows the user to include the unavoidable imprecision, which stems from the lack of available information or randomness of a future situation, and to quantify the qualitative criteria, of which measurement of the exact value is difficult [21].

If $X$ is a collection of objects generically denoted by $x$, then a fuzzy set $A$ in $X$ is a set of ordered pairs:

$$
\tilde{A}=\left\{\left(x, \mu_{\tilde{A}}(x)\right) \mid x \in X\right\},
$$

$\mu_{\tilde{A}}(x)$ is called the membership function of $x$ in $\tilde{A}$ that maps $X$ to the membership space $M$ [20].

A fuzzy number, $\tilde{A}$, is a convex normalized fuzzy set, $\tilde{A}$, of the rael line, $\mathbb{R}$, such that:

1. There exists exactly one $x_{0} \in \mathbb{R}$ with $\mu_{\tilde{A}}\left(x_{0}\right)=1$ ( $x_{0}$ is called the mean value or mode of $A$ );

2. $\mu_{\tilde{A}}(x)$ is piecewise continuous and in case of LR (left-right) type fuzzy numbers;

3. There exist reference functions $L$ and $R$, and scalars $e^{L}$ and $e^{R}$ such that:

$$
\mu_{\tilde{A}}(x)= \begin{cases}L\left(\frac{m-x}{e^{L}}\right) & \text { for } x \leq m \\ R\left(\frac{x-m}{e^{R}}\right) & \text { for } x \geq m\end{cases}
$$

Triangular fuzzy numbers as one of the most commonly used types of LR fuzzy numbers will be used in this study. A triangular fuzzy number, $\tilde{A}$, shown in Figure 1 , can be denoted as $(l, m, r)$ with membership function $\mu_{\tilde{A}}(x)$ :

$$
\mu_{\tilde{A}}(x)= \begin{cases}1-\frac{m-x}{m-l} & \text { for } l \leq x \leq m \\ 1-\frac{x-m}{r-m} & \text { for } m \leq x \leq r, \\ 0 & \text { elsewhere }\end{cases}
$$

where $m$ is the mode of triangular fuzzy number, $\tilde{A} ; l$ is the right end point of $\tilde{A}$; and $r$ is the left end point of $\tilde{A}$. 


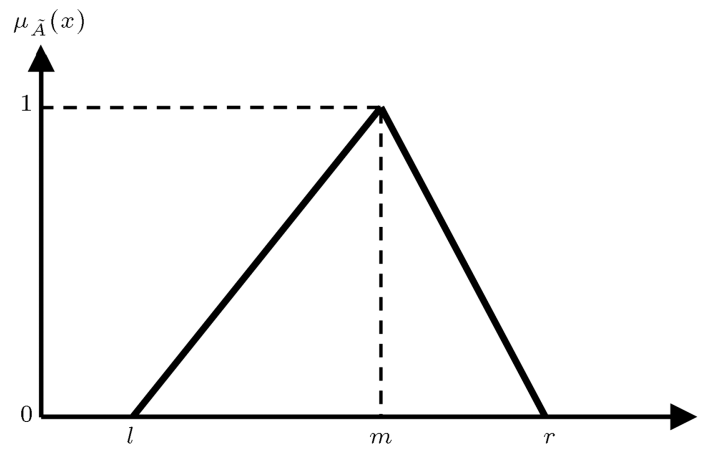

Figure 1. A triangular fuzzy number.

\subsection{Determining the relative weights of decision makers}

The appropriate PDS cannot be properly chosen using a single DM since various factors affecting the performance of a PDS (such as technical, economical, etc.) would not be taken into account, appropriately. Even if we assume a group of experts with common interests, individual group members will each have their own motivations and, hence, will be in conflict on certain issues [22].

Having a heterogeneous group of experts can be an advantage over a homogenous group through the consideration of all knowledge and compensation for dissenting points of view [23].

Different DMs have different levels of knowledge and experience, as well as various organizational positions. It is, therefore, necessary to use an appropriate method to deal with the relative weights of different experts constituting a heterogeneous group.

The methodology used for determining the relative weights of DMs was originally developed by Azadi et al. [23]. They presented an approach to reach an overall group decision through aggregating opinions elicited from different experts to solve a rangeland management decision problem. The modified approach is briefly explained below.

Let $s_{c i}^{a}$ be the score given to the evaluation criterion " $c$ " by $\mathrm{DM}_{i}$ against decision alternative $a$. The absolute value of the difference between opinions of $\mathrm{DM}_{i}$ and $\mathrm{DM}_{j}$ for decision alternative $a, \Delta_{i j}^{a}$, is defined by:

$$
\Delta_{i j}^{a}=\sum_{c=1}^{\mathcal{C}}\left|s_{c i}^{a}-s_{c j}^{a}\right|,
$$

where $\mathcal{C}$ is the number of decision criteria. The sum of absolute differences between $\mathrm{DM}_{i}$ and all other DMs for decision alternative $a, \Delta_{i}^{a}$, is defined by:

$$
\Delta_{i}^{a}=\sum_{j=1 \& j \neq i}^{\mathcal{N}} \Delta_{i j}^{a},
$$

where $\mathcal{N}$ is the number of decision makers. Finally, the relative weight assigned to $\mathrm{DM}_{i}$ for decision alternative $a$ by all group members, ${ }^{g} \lambda_{i}^{a}$, is:

$$
{ }^{g} \lambda_{i}^{a}=\frac{\frac{1}{\Delta_{i}^{a}}}{\sum_{j=1}^{\mathcal{N}}\left(\frac{1}{\Delta_{j}^{a}}\right)} .
$$

As it could be seen in Eqs. (7)-(9), the relative weights of DMs are calculated based on the fact that "The more a DMs opinion is different from the other group members, the less weight will be assigned by the group".

In this research, the opinion of the group manager who conducts the decision making process is also taken into account in order to determine the relative weight of decision makers more accurately. Considering the group manager opinion, ${ }^{m} \lambda_{i}$, the relative weight of decision makers will be determined as follows:

$$
\lambda_{i}^{a}=\beta\left({ }^{m} \lambda_{i}\right)+(1-\beta)\left({ }^{g} \lambda_{i}^{a}\right),
$$

where $\lambda_{i}^{a}$ is the final relative weight of $\mathrm{DM}_{i}$ for the decision alternative $a$. $0 \leq \beta \leq 1$ shows the importance of ${ }^{m} \lambda_{i}$ over ${ }^{g} \lambda_{i}^{a}$.

\subsection{Constructing fuzzy numbers}

In this study, the scores given to criterion $c$ against alternative $a$ by different DMs are aggregated and converted to a single triangular fuzzy number. Assume that $\mathcal{N}$ different DMs have assigned scores $0 \leq$ $s_{c 1}^{a}, \ldots, s_{c \mathcal{N}}^{a} \leq \mathcal{S}$, grading a same criterion against alternative $a$, and there exists at least one pair of $i \neq j$ so that $s_{c i}^{a} \neq s_{c j}^{a}$; for constructing a triangular fuzzy number of scores given to criterion $c$ against alternative $a, \tilde{s}_{c}^{a}$, we do as follows [24]:

1. To estimate the mode of the triangular fuzzy number, $m_{c}^{a}$, we use the weighted average of $s_{c i}^{a}$. $\mathrm{Eq}$. (11) gives the mode of the fuzzy number:

$$
m_{c}^{a}=\sum_{i=1}^{\mathcal{N}} \lambda_{i}^{a} S_{c i}^{a}
$$

where $\lambda_{i}^{a}$ is the relative weight of $\mathrm{DM}_{i}$ for decision alternative $a$, which is calculated as explained in the previous section;

2. To estimate the left and right end points of the triangular fuzzy number, $l_{c}^{a}$ and $r_{c}^{a}$, we need to know two more parameters: the mean deviation of the fuzzy number $\left(\sigma_{c}^{a}\right)$ and the ratio of the left spread to the right spread $\left(\eta_{c}^{a}\right)$. Because $\sigma_{c}^{a}$ and $\eta_{c}^{a}$ are again dependent on $l_{c}^{a}$ and $r_{c}^{a}$, they are approximated as follows:

$$
\begin{aligned}
\sigma_{c}^{a} & =\sum_{i=1}^{\mathcal{N}} \lambda_{i}^{a}\left|s_{c i}^{a}-m_{c}^{a}\right|, \\
\eta_{c}^{a} & =\frac{m_{c}^{a}-{ }^{l} g_{c}^{a}}{{ }^{r} g_{c}^{a}-m_{c}^{a}}
\end{aligned}
$$


${ }^{l} g_{c}^{a}$ and ${ }^{r} g_{c}^{a}$ are calculated as follows:

$$
\begin{aligned}
& { }^{l} g_{c}^{a}=\frac{\sum_{i \in \mathbb{A}} \lambda_{i}^{a} s_{c i}^{a}}{\sum_{i \in \mathbb{A}} \lambda_{i}^{a}}, \\
& { }^{r} g_{c}^{a}=\frac{\sum_{i \in \mathbb{B}} \lambda_{i}^{a} s_{c i}^{a}}{\sum_{i \in \mathbb{B}} \lambda_{i}^{a}},
\end{aligned}
$$

where $\in\{1, \ldots, \mathcal{N}\}, \mathbb{A}=\left\{i \mid s_{c i}^{a}<m_{c}^{a}, i \in \mathbb{I}\right\}, \mathbb{B}=$ $\left\{i \mid s_{c i}^{a}>m_{c}^{a}, i \in \mathbb{I}\right\}$.

Once $\sigma_{c}^{a}$ and $\eta_{c}^{a}$ are calculated, $l_{c}^{a}$ and $r_{c}^{a}$ could be defined by:

$$
\begin{aligned}
& l_{c}^{a}=m_{c}^{a}-\frac{3\left(1+\eta_{c}^{a}\right)\left(\eta_{c}^{a}\right)\left(\sigma_{c}^{a}\right)}{1+\left(\eta_{c}^{a}\right)^{2}}, \\
& r_{c}^{a}=m_{c}^{a}+\frac{3\left(1+\eta_{c}^{a}\right)\left(\sigma_{c}^{a}\right)}{1+\left(\eta_{c}^{a}\right)^{2}}
\end{aligned}
$$

The exception of the proposed method is that the fuzzy numbers, constructed in this way, have predefined boundaries that are the range in which the original crisp scores have laid. So, if the end points of a fuzzy number fall beyond boundaries, it will be truncated. In this study, the scores are in the range of 0 to 1 since they are obtained by the AHP methodology:

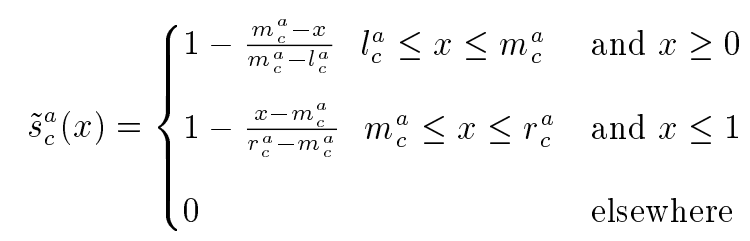

$\tilde{s}_{c}^{a}(x)$ is the truncated membership function. Figure 2 shows an example of a truncated fuzzy number that its left end point has exceeded the zero boundary.

\subsection{Fuzzy-AHP Multi-Criteria Group Decision Making (FMCGDM) methodology}

The flowchart diagram of the decision making process by the proposed integrated FMCGDM method is depicted in Figure 3. As shown in this figure, the decision making process is performed in five steps. At the first step, the alternative project delivery systems, decision criteria, and decision makers are determined.

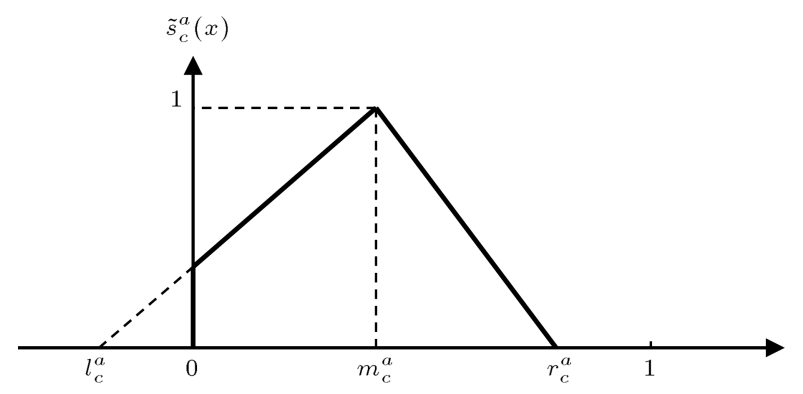

Figure 2. Truncated triangular fuzzy number.
Moreover, the relative weight and score of each criterion is evaluated using AHP technique. The relative weights of decision makers are then determined using the method proposed in Section 2.3.

At the second step, fuzzification of criteria weights and scores is performed. For this purpose, the triangular fuzzy numbers of criteria weights and scores are constructed using the proposed methodology explained in Section 2.4.

At the third step, the aggregation process is performed. In this step, the obtained fuzzy numbers of criteria scores and weights are multiplied and summed up for each PDS option using a methodology based on Zadeh's extension principle [13] and performing interval arithmetic at discrete $\alpha$-cuts. The aggregation process is done in the following 5 steps:

1. A particular $\alpha$-cut value is selected;

2. The associated crisp values of the fuzzy numbers of criteria weights and scores are determined;

3. The associated crisp values of fuzzy numbers of criteria weights and scores are multiplied;

4. Steps 1-3 are repeated for as many values of $\alpha$-cut as needed to refine the solution. Coverage of the entire range of $\alpha$-cut makes the output of the model a fuzzy number;

5. The produced fuzzy numbers are summed up and the final score of each PDS alternative is determined as a fuzzy number.

Defuzzification of the fuzzy scores of each PDS option is done in step 4 using the Center Of Area (COA) method. Finally, selection of the best alternative PDS is done in step 5. Sensitivity analysis is also conducted on the final obtained results in order to assure their validity as will be explained later.

\section{Application of the proposed methodology}

The proposed fuzzy-AHP group multi-criteria decision making method is implemented on a real-world dam and hydro power plant project entitled "Rudbar Lorestan" to evaluate its applicability and performance. Rudbar Lorestan dam and hydropower plant project are located on Rudbar River (in upper East of Dez River catchment area) in Zagros Mountain, and nearly 100 kilometers distant from South of Aligoodarz city in Lorestan Province, Iran. The following section explains in detail how the best alternative PDS is selected using the proposed methodology.

\subsection{Step 1: Definition-evaluation \\ 3.1.1. Defining PDS options}

In this case study, four project delivery system options are evaluated including Design/Bid/Build (DBB), Design-Build (DB), Construction Management- 


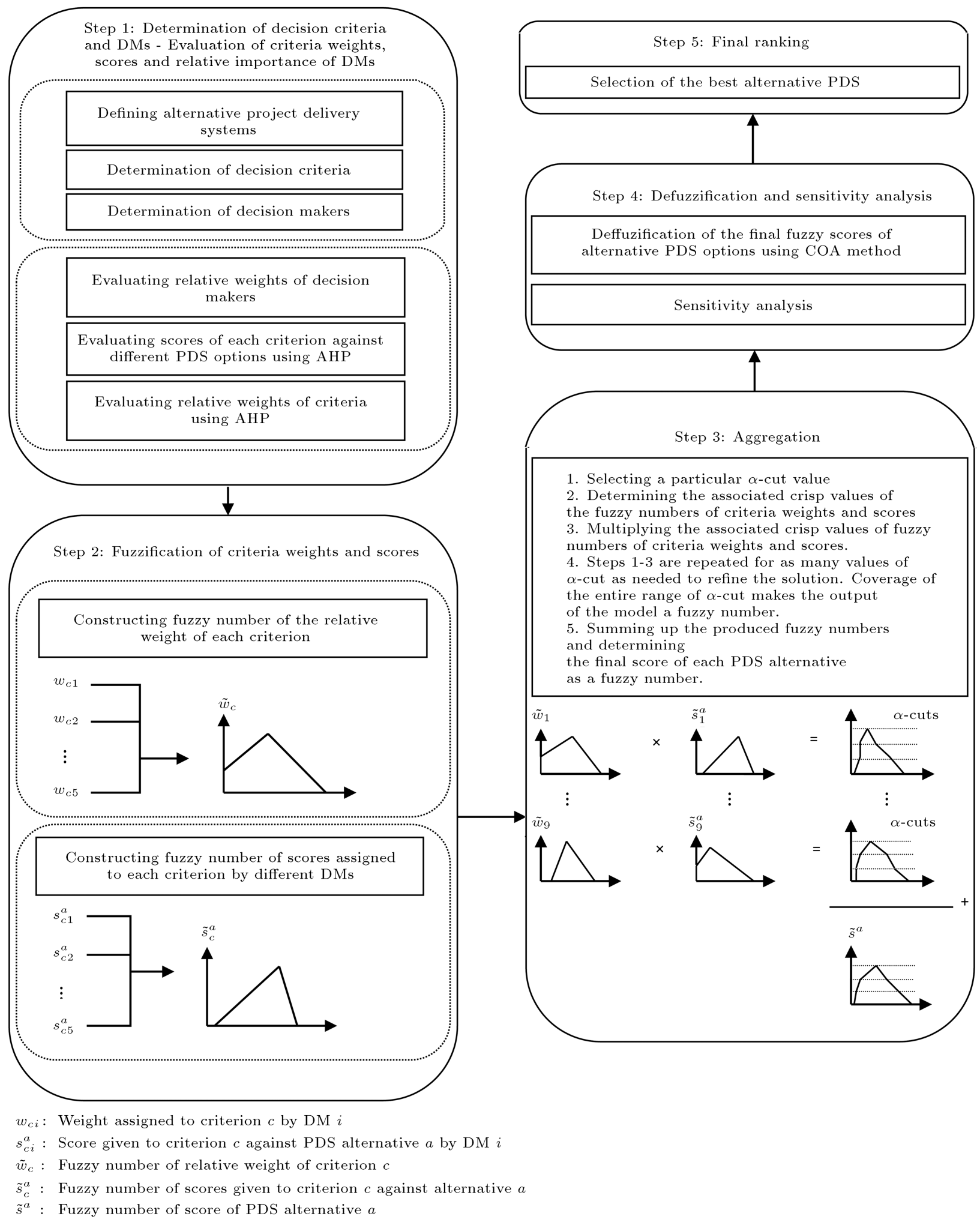

Figure 3. The flowchart diagram of the proposed fuzzy-AHP group multi-criteria decision making method.

Agency (CM-A), and Construction Management-at Risk (CM-R). DBB system, which is often referred to as the "traditional" method, is the most common project delivery option. There are three parties involved in this method, i.e. owner, designer, and builder. The owner has two separate contracts by which the responsibilities for the design and construction portions of work are assigned to the designer and builder, respectively. DB system has proven to be effective in projects where time and 
Table 2. Pairwise comparison of different criteria by $\mathrm{DM}_{1}$.

\begin{tabular}{ccccccccccc}
\hline $\begin{array}{c}\mathbf{D M}_{\mathbf{1}} \\
\text { IR=0.03 }\end{array}$ & $\boldsymbol{C}_{\mathbf{1}}$ & $\boldsymbol{C}_{\mathbf{2}}$ & $\boldsymbol{C}_{\mathbf{3}}$ & $\boldsymbol{C}_{\boldsymbol{4}}$ & $\boldsymbol{C}_{\mathbf{5}}$ & $\boldsymbol{C}_{\boldsymbol{6}}$ & $\boldsymbol{C}_{\boldsymbol{7}}$ & $\boldsymbol{C}_{\boldsymbol{8}}$ & $\boldsymbol{C}_{\mathbf{9}}$ & $\begin{array}{c}\text { Criteria } \\
\text { weight }\end{array}$ \\
\hline$C_{1}$ & 1 & $1 / 2$ & $1 / 4$ & $1 / 5$ & $1 / 2$ & $1 / 3$ & $1 / 3$ & $1 / 3$ & $1 / 2$ & $\mathbf{0 . 0 3 8}$ \\
$C_{2}$ & & 1 & $1 / 3$ & $1 / 3$ & 1 & $1 / 3$ & $1 / 3$ & $1 / 2$ & 2 & $\mathbf{0 . 0 6 1}$ \\
$C_{3}$ & & & 1 & $1 / 2$ & 2 & $1 / 2$ & $1 / 2$ & 3 & 3 & $\mathbf{0 . 1 3 6}$ \\
$C_{4}$ & & & & 1 & 2 & $1 / 2$ & $1 / 2$ & 2 & 4 & $\mathbf{0 . 1 5 9}$ \\
$C_{5}$ & & & & & 1 & $1 / 3$ & $1 / 2$ & 1 & 2 & $\mathbf{0 . 0 7 4}$ \\
$C_{6}$ & & & & & & 1 & 1 & 3 & 3 & $\mathbf{0 . 2 0 2}$ \\
$C_{7}$ & & & & & & 1 & 3 & 5 & $\mathbf{0 . 2 0 3}$ \\
$C_{8}$ & & & & & & & & 1 & 3 & $\mathbf{0 . 0 8 3}$ \\
$C_{9}$ & & & & & & & & 1 & $\mathbf{0 . 0 4 3}$ \\
\hline
\end{tabular}

cost controls are priorities and where a single source of design and construction is a good approach to meet those priorities [25]. In this type of PDS, the owner assigns the responsibilities for both design and construction portions of work to a design-builder. In CM-R system, an architect/engineer is selected to design the project and, separately, an at risk construction manager is selected. A construction manager has to provide construction leadership and perform administration and management within a defined scope of services. The qualified construction manager is also the constructor of the project, acting much like a general contractor during the construction phase and taking on the responsibilities of a constructor [25]. Finally, in CM-A, an architect/engineer is selected to design the project. The construction portion of work is assigned to a builder similar to what mentioned before for the DBB option. At the same time, a separate selection is made for a construction manager to serve as an agent for the owner, providing administration and management services $[9,26]$.

\subsubsection{Determination of decision criteria}

Careful selection of decision criteria plays an important role to select the best PDS option, efficiently. Speed, certainty, flexibility, quality, complexity, risk allocation, responsibility, arbitration and dispute, and price competition are often identified as the common indicators for PDS selection [3]. The major criteria used in this case study for the evaluation of PDS options is the result of multiple brainstorming sessions held by decision makers. These criteria include time certainty, decrease in project duration, cost certainty, project quality, availability of capable bidders, flexibility against changes, project risks and uncertainties, project coordination and integrity, and the required personnel involved in the owner entity.

\subsubsection{Determination of decision makers}

A group consisted of five experts were used as decision makers in this research. These experts had a thorough
Table 3. Pairwise comparison of different PDS options against the first criterion (time certainty) by $\mathrm{DM}_{1}$.

\begin{tabular}{cccccc}
\hline $\begin{array}{c}\mathbf{D M}_{\mathbf{1}} \\
\mathbf{C}_{\mathbf{1}}\end{array}$ & $\mathbf{C M - A}$ & $\mathbf{D B}$ & $\mathbf{D B B}$ & $\mathbf{C M}-\mathbf{R}$ & Score \\
$\mathbf{I R = 0 . 0 4}$ & & & & & \\
\hline $\mathrm{CM}-\mathrm{A}$ & 1 & $1 / 5$ & 3 & $1 / 4$ & $\mathbf{0 . 1 1 1}$ \\
DB & & 1 & 7 & 2 & $\mathbf{0 . 5 0 9}$ \\
DBB & & & 1 & $1 / 6$ & $\mathbf{0 . 0 5 3}$ \\
$\mathrm{CM}-\mathrm{R}$ & & & & 1 & $\mathbf{0 . 3 2 7}$ \\
\hline
\end{tabular}

knowledge of different PDS options as well as a great experience of the performance of different PDS options.

\subsubsection{Evaluation of Criteria Weights and Scores and Relative Importance of DMs}

After defining the alternative PDS options and the decision criteria, a group, consisting of five DMs, assigned the scores of each criterion against different PDS options using AHP method. The relative weight of each criterion was also determined using AHP method. Tables 2 and 3 present a sample pairwise comparison done for the evaluation of criteria weights and scores of each PDS option. Tables 4 and 5 represent the final resulted crisp weights of different criteria and the final resulted crisp scores of each criterion against different PDS options determined based on the opinions of DMs, respectively. The data represented in Tables 4 and 5 acts as an input for the next steps.

Having the results of pairwise comparisons done by the AHP method, the relative weights of each decision maker was determined using Eqs. (7) to (10). Tables 6 and 7 show the details of computations performed using Eqs. (7) to (10). Table 8 shows the final relative weights of different DMs, which are calculated using Eq. (10). In this table, $\lambda_{i}^{a}$ is the final relative weight of $\mathrm{DM}_{i}$ for the decision alternative $a$. $0 \leq \beta \leq 1$ shows the importance of ${ }^{m} \lambda_{i}$ over ${ }^{g} \lambda_{i}^{a}$.

It should be stated that in this research, AHP was used due to its simplicity. In other methods like ANP, the number of pairwise comparisons is greater than that in conventional AHP. However, a comparison 
Table 4. The resulted crisp weight of the criteria determined based on the opinions of different DMs.

\begin{tabular}{cccccccccc}
\hline Number of DM & $\boldsymbol{C}_{\mathbf{1}}$ & $\boldsymbol{C}_{\mathbf{2}}$ & $\boldsymbol{C}_{\mathbf{3}}$ & $\boldsymbol{C}_{\boldsymbol{4}}$ & $\boldsymbol{C}_{\mathbf{5}}$ & $\boldsymbol{C}_{\boldsymbol{6}}$ & $\boldsymbol{C}_{\boldsymbol{7}}$ & $\boldsymbol{C}_{\mathbf{8}}$ & $\boldsymbol{C}_{\mathbf{9}}$ \\
\hline $\mathrm{DM}_{1}$ & $\mathbf{0 . 0 3 8}$ & $\mathbf{0 . 0 6 1}$ & $\mathbf{0 . 1 3 6}$ & $\mathbf{0 . 1 5 9}$ & $\mathbf{0 . 0 7 4}$ & $\mathbf{0 . 2 0 2}$ & $\mathbf{0 . 2 0 3}$ & $\mathbf{0 . 0 8 3}$ & $\mathbf{0 . 0 4 3}$ \\
$\mathrm{DM}_{2}$ & 0.114 & 0.125 & 0.206 & 0.161 & 0.082 & 0.068 & 0.112 & 0.091 & 0.041 \\
$\mathrm{DM}_{3}$ & 0.060 & 0.080 & 0.110 & 0.230 & 0.030 & 0.020 & 0.180 & 0.220 & 0.080 \\
$\mathrm{DM}_{4}$ & 0.089 & 0.051 & 0.216 & 0.142 & 0.052 & 0.139 & 0.208 & 0.073 & 0.030 \\
$\mathrm{DM}_{5}$ & 0.055 & 0.042 & 0.076 & 0.155 & 0.125 & 0.096 & 0.120 & 0.179 & 0.152 \\
\hline
\end{tabular}

Table 5. The resulted crisp scores of each criterion against different PDS options.

\begin{tabular}{|c|c|c|c|c|c|c|c|c|c|c|}
\hline $\begin{array}{c}\text { PDS } \\
\text { Options }\end{array}$ & $\begin{array}{c}\text { Criteria } \rightarrow \\
\text { Number of } \mathrm{DMs} \downarrow\end{array}$ & $C_{1}$ & $C_{2}$ & $C_{3}$ & $C_{4}$ & $C_{5}$ & $C_{6}$ & $C_{7}$ & $C_{8}$ & $C_{9}$ \\
\hline \multirow{5}{*}{ CM-A } & $\mathrm{DM}_{1}$ & 0.111 & 0.111 & 0.147 & 0.564 & 0.210 & 0.344 & 0.344 & 0.112 & 0.116 \\
\hline & $\mathrm{DM}_{2}$ & 0.137 & 0.104 & 0.103 & 0.551 & 0.218 & 0.275 & 0.338 & 0.146 & 0.149 \\
\hline & $\mathrm{DM}_{3}$ & 0.271 & 0.192 & 0.107 & 0.293 & 0.296 & 0.398 & 0.398 & 0.106 & 0.366 \\
\hline & $\mathrm{DM}_{4}$ & 0.139 & 0.124 & 0.093 & 0.618 & 0.069 & 0.125 & 0.115 & 0.491 & 0.251 \\
\hline & $\mathrm{DM}_{5}$ & 0.073 & 0.078 & 0.112 & 0.059 & 0.167 & 0.243 & 0.105 & 0.071 & 0.474 \\
\hline \multirow{5}{*}{ DB } & $\mathrm{DM}_{1}$ & 0.509 & 0.509 & 0.495 & 0.068 & 0.116 & 0.089 & 0.089 & 0.288 & 0.210 \\
\hline & $\mathrm{DM}_{2}$ & 0.347 & 0.472 & 0.462 & 0.152 & 0.147 & 0.122 & 0.133 & 0.254 & 0.283 \\
\hline & $\mathrm{DM}_{3}$ & 0.155 & 0.250 & 0.339 & 0.199 & 0.209 & 0.119 & 0.119 & 0.312 & 0.238 \\
\hline & $\mathrm{DM}_{4}$ & 0.487 & 0.256 & 0.541 & 0.049 & 0.085 & 0.044 & 0.566 & 0.291 & 0.209 \\
\hline & $\mathrm{DM}_{5}$ & 0.221 & 0.209 & 0.210 & 0.239 & 0.333 & 0.117 & 0.209 & 0.484 & 0.170 \\
\hline \multirow{5}{*}{ DBB } & $\mathrm{DM}_{1}$ & 0.053 & 0.053 & 0.067 & 0.238 & 0.610 & 0.517 & 0.517 & 0.068 & 0.064 \\
\hline & $\mathrm{DM}_{2}$ & 0.065 & 0.150 & 0.134 & 0.243 & 0.553 & 0.520 & 0.472 & 0.066 & 0.063 \\
\hline & $\mathrm{DM}_{3}$ & 0.211 & 0.168 & 0.091 & 0.269 & 0.263 & 0.367 & 0.367 & 0.069 & 0.041 \\
\hline & $\mathrm{DM}_{4}$ & 0.071 & 0.082 & 0.058 & 0.210 & 0.624 & 0.574 & 0.063 & 0.050 & 0.078 \\
\hline & $\mathrm{DM}_{5}$ & 0.310 & 0.314 & 0.295 & 0.436 & 0.333 & 0.160 & 0.570 & 0.296 & 0.068 \\
\hline \multirow{5}{*}{ CM-R } & $\mathrm{DM}_{1}$ & 0.327 & 0.327 & 0.291 & 0.130 & 0.064 & 0.050 & 0.050 & 0.532 & 0.610 \\
\hline & $\mathrm{DM}_{2}$ & 0.452 & 0.274 & 0.301 & 0.053 & 0.082 & 0.082 & 0.057 & 0.534 & 0.505 \\
\hline & $\mathrm{DM}_{3}$ & 0.363 & 0.390 & 0.463 & 0.239 & 0.232 & 0.116 & 0.116 & 0.513 & 0.355 \\
\hline & $\mathrm{DM}_{4}$ & 0.303 & 0.538 & 0.308 & 0.123 & 0.222 & 0.258 & 0.256 & 0.168 & 0.462 \\
\hline & $\mathrm{DM}_{5}$ & 0.395 & 0.400 & 0.383 & 0.266 & 0.167 & 0.480 & 0.116 & 0.149 & 0.288 \\
\hline
\end{tabular}

Table 6. Determining relative weight of each DM for the 1st PDS option (CM-A) $(\beta=0.5)$.

\begin{tabular}{ccccc}
\hline $\begin{array}{c}\text { Decision } \\
\text { makers }\end{array}$ & $\boldsymbol{\Delta}_{\boldsymbol{i}}^{\mathbf{1}}$ & ${ }^{\boldsymbol{g}} \boldsymbol{\lambda}_{\boldsymbol{i}}^{\mathbf{1}}$ & ${ }^{\boldsymbol{m}_{\boldsymbol{i}} \boldsymbol{\lambda}_{\boldsymbol{i}}^{\mathbf{1}}}$ & $\boldsymbol{\lambda}_{\boldsymbol{i}}^{\mathbf{1}}$ \\
\hline $\mathrm{DM}_{1}$ & 3.887 & 0.237 & 0.160 & $\mathbf{0 . 1 9 8}$ \\
$\mathrm{DM}_{2}$ & 3.617 & 0.255 & 0.250 & $\mathbf{0 . 2 5 2}$ \\
$\mathrm{DM}_{3}$ & 5.097 & 0.181 & 0.150 & $\mathbf{0 . 1 6 5}$ \\
$\mathrm{DM}_{4}$ & 5.701 & 0.161 & 10.250 & $\mathbf{0 . 2 0 6}$ \\
$\mathrm{DM}_{5}$ & 5.530 & 0.166 & 0.190 & $\mathbf{0 . 1 7 8}$ \\
$\mathrm{SUM}$ & & 1.000 & 1.000 & 1.000 \\
\hline
\end{tabular}

between the results of AHP and ANP could be done in the future research.

\subsection{Step 2: Fuzzification of criteria weights and scores}

At the second step, fuzzification of criteria weights and scores was performed. For this purpose, the scores
Table 7. Determining relative weight of each DM for decision criteria $(\beta=0.5)$.

\begin{tabular}{ccccc}
\hline $\begin{array}{c}\text { Decision } \\
\text { makers }\end{array}$ & $\boldsymbol{\Delta}_{\boldsymbol{i}}^{C}$ & ${ }^{g} \boldsymbol{\lambda}_{\boldsymbol{i}}^{C}$ & ${ }^{\boldsymbol{m}_{\boldsymbol{i}} \boldsymbol{C}}$ & $\boldsymbol{\lambda}_{\boldsymbol{i}}^{\boldsymbol{C}}$ \\
\hline $\mathrm{DM}_{1}$ & 1.832 & 0.220 & 0.160 & $\mathbf{0 . 1 9 0}$ \\
$\mathrm{DM}_{2}$ & 1.965 & 0.205 & 0.250 & $\mathbf{0 . 2 2 8}$ \\
$\mathrm{DM}_{3}$ & 2.275 & 0.177 & 0.150 & $\mathbf{0 . 1 6 4}$ \\
$\mathrm{DM}_{4}$ & 1.871 & 0.216 & 0.250 & $\mathbf{0 . 2 3 3}$ \\
$\mathrm{DM}_{5}$ & 2.225 & 0.181 & 0.190 & $\mathbf{0 . 1 8 6}$ \\
$\mathrm{SUM}$ & & 1.00 & 1.00 & 1.000 \\
\hline
\end{tabular}

given by different DMs were aggregated and converted to a fuzzy number.

The triangular fuzzy numbers of relative weights of criteria were calculated using Eqs. (11) to (17). The resulted fuzzy numbers of criteria weights are presented in Table 9. Similarly, the triangular fuzzy numbers of the scores given to each criterion against different 
Table 8. The relative weights of decision makers $(\beta=0.5)$.

\begin{tabular}{|c|c|c|c|c|c|c|c|c|c|c|c|}
\hline & \multirow{3}{*}{${ }^{m} \lambda_{i}$} & \multicolumn{8}{|c|}{ PDS options } & \multicolumn{2}{|c|}{ Criteria } \\
\hline & & \multicolumn{2}{|c|}{$\mathrm{O}_{1}(\mathrm{CM}-\mathrm{A})$} & \multicolumn{2}{|c|}{$\mathrm{O}_{2}(\mathrm{DB})$} & \multicolumn{2}{|c|}{$\mathrm{O}_{3}(\mathrm{DBB})$} & \multicolumn{2}{|c|}{$\mathrm{O}_{4}(\mathrm{CM}-\mathrm{R})$} & \multirow[b]{2}{*}{${ }^{g} \lambda_{i}^{C}$} & \multirow[b]{2}{*}{$\lambda_{i}^{C}$} \\
\hline & & ${ }^{g} \boldsymbol{\lambda}_{i}^{1}$ & $\lambda_{i}^{1}$ & ${ }^{g} \boldsymbol{\lambda}_{i}^{2}$ & $\lambda_{i}^{2}$ & ${ }^{g} \boldsymbol{\lambda}_{i}^{3}$ & $\lambda_{i}^{3}$ & ${ }^{g} \lambda_{i}^{4}$ & $\lambda_{i}^{4}$ & & \\
\hline $\mathrm{DM}_{1}$ & 0.160 & 0.237 & 0.198 & 0.213 & 0.187 & 0.237 & 0.199 & 0.211 & 0.185 & 0.220 & 0.190 \\
\hline $\mathrm{DM}_{2}$ & 0.250 & 0.255 & 0.252 & 0.231 & 0.240 & 0.256 & 0.253 & 0.209 & 0.230 & 0.205 & 0.228 \\
\hline $\mathrm{DM}_{3}$ & 0.150 & 0.181 & 0.165 & 0.223 & 0.187 & 0.205 & 0.177 & 0.223 & 0.187 & 0.177 & 0.164 \\
\hline $\mathrm{DM}_{4}$ & 0.250 & 0.161 & 0.206 & 0.170 & 0.210 & 0.179 & 0.214 & 0.184 & 0.217 & 0.216 & 0.233 \\
\hline $\mathrm{DM}_{5}$ & 0.190 & 0.166 & 0.178 & 0.163 & 0.177 & 0.123 & 0.157 & 0.173 & 0.181 & 0.181 & 0.186 \\
\hline SUM & 1.000 & 1.000 & 1.000 & 1.000 & 1.000 & 1.000 & 1.000 & 1.000 & 1.000 & 1.000 & 1.000 \\
\hline
\end{tabular}

Table 9. The constructed triangular fuzzy numbers of relative weights of criteria.

\begin{tabular}{|c|c|c|c|c|c|c|c|c|c|c|}
\hline & \multicolumn{10}{|c|}{ AHP results } \\
\hline & $\lambda_{i}^{c}$ & $C_{1}$ & $C_{2}$ & $C_{3}$ & $C_{4}$ & $C_{5}$ & $C_{6}$ & $C_{7}$ & $C_{8}$ & $C_{9}$ \\
\hline $\mathrm{DM}_{1}$ & 0.190 & 0.038 & 0.061 & 0.136 & 0.159 & 0.074 & 0.202 & 0.203 & 0.083 & 0.043 \\
\hline $\mathrm{DM}_{2}$ & 0.228 & 0.114 & 0.125 & 0.206 & 0.161 & 0.082 & 0.068 & 0.112 & 0.091 & 0.041 \\
\hline $\mathrm{DM}_{3}$ & 0.164 & 0.060 & 0.080 & 0.110 & 0.230 & 0.030 & 0.020 & 0.180 & 0.220 & 0.080 \\
\hline $\mathrm{DM}_{4}$ & 0.233 & 0.089 & 0.051 & 0.216 & 0.142 & 0.052 & 0.139 & 0.208 & 0.073 & 0.030 \\
\hline $\mathrm{DM}_{5}$ & 0.186 & 0.055 & 0.042 & 0.076 & 0.155 & 0.125 & 0.096 & 0.120 & 0.179 & 0.152 \\
\hline \multicolumn{11}{|c|}{ Calculations } \\
\hline${ }^{l} g_{c}$ & & 0.051 & 0.051 & 0.107 & 0.154 & 0.043 & 0.063 & 0.116 & 0.082 & 0.038 \\
\hline${ }^{r} g_{c}$ & & 0.101 & 0.106 & 0.211 & 0.230 & 0.093 & 0.167 & 0.199 & 0.198 & 0.118 \\
\hline$\sigma_{c}$ & & 0.025 & 0.026 & 0.051 & 0.021 & 0.024 & 0.051 & 0.040 & 0.053 & 0.037 \\
\hline$\eta_{c}$ & & 0.854 & 0.643 & 0.854 & 0.196 & 1.522 & 0.733 & 1.419 & 0.537 & 0.537 \\
\hline \multicolumn{11}{|c|}{ Triangular fuzzy numbers } \\
\hline$l_{c}$ & & 0.005 & 0.014 & 0.014 & 0.152 & 0.000 & 0.000 & 0.027 & 0.021 & 0.000 \\
\hline$m_{c}$ & & 0.074 & 0.073 & 0.155 & 0.166 & 0.073 & 0.107 & 0.164 & 0.123 & 0.066 \\
\hline$r_{c}$ & & 0.155 & 0.164 & 0.321 & 0.238 & 0.127 & 0.279 & 0.261 & 0.311 & 0.197 \\
\hline
\end{tabular}

PDS options were calculated. As an example, the fuzzy number of scores given to each criterion for the first PDS option, i.e. the Construction ManagementAgency, is presented in Table 10.

\subsection{Step 3: Aggregation}

In the aggregation phase, the obtained fuzzy numbers of criteria scores and weights were multiplied and summed up for each PDS option. The aggregation process was done using the extension principle as explained in Section 2.5. For this purpose, 11 different $\alpha$-cuts were selected. Tables 11 and 12 show the left and right values of the scores of alternative PDS options at different $\alpha$-cuts, respectively.

\subsection{Step 4: Defuzzification and sensitivity analysis}

3.4.1. Defuzzification

Defuzzification of fuzzy numbers is an important procedure for the risk assessment in fuzzy environments.
Defuzzification is the operation of producing a nonfuzzy number, a single value that adequately represents the fuzzy number [27]. There are various methods for defuzzification. In this research, however, the Center Of Area (COA) method was used for defuzzification due to its simplicity and avoidance of complicated calculations [28-30,32]. The final ranking of different PDS options is presented in Table 13.

\subsubsection{Sensitivity analysis}

The PDS options ranking has been obtained based on the assumption that the weights that each DM receives from the group $\left({ }^{g} \lambda_{i}^{a}\right)$ and the group manager (who conducts the decision making process) $\left({ }^{m} \lambda_{i}\right)$ have the same degree of importance $(\beta=0.5)$. In this section, the sensitivity of the obtained results is examined against different values of $\beta$. Therefore, the previous calculations are repeated for $\beta=\{0.0,0.1,0.3,0.5,0.7,1.0\}$ and the final score and rank of each PDS option are determined. In Table 14, the final ranking of 
Table 10. The constructed triangular fuzzy numbers of scores given to different criteria for the first PDS option (CM-A).

\begin{tabular}{|c|c|c|c|c|c|c|c|c|c|c|}
\hline & \multicolumn{10}{|c|}{ AHP results } \\
\hline & $\lambda_{i}^{1}$ & $C_{1}$ & $C_{2}$ & $C_{3}$ & $C_{4}$ & $C_{5}$ & $C_{6}$ & $C_{7}$ & $C_{8}$ & $C_{9}$ \\
\hline $\mathrm{DM}_{1}$ & 0.198 & 0.111 & 0.111 & 0.147 & 0.564 & 0.210 & 0.344 & 0.344 & 0.112 & 0.116 \\
\hline $\mathrm{DM}_{2}$ & 0.252 & 0.137 & 0.104 & 0.103 & 0.551 & 0.218 & 0.275 & 0.338 & 0.146 & 0.149 \\
\hline $\mathrm{DM}_{3}$ & 0.165 & 0.271 & 0.192 & 0.107 & 0.293 & 0.296 & 0.398 & 0.398 & 0.106 & 0.366 \\
\hline $\mathrm{DM}_{4}$ & 0.206 & 0.139 & 0.124 & 0.093 & 0.618 & 0.069 & 0.125 & 0.115 & 0.491 & 0.251 \\
\hline $\mathrm{DM}_{5}$ & 0.178 & 0.073 & 0.078 & 0.112 & 0.059 & 0.167 & 0.243 & 0.105 & 0.071 & 0.474 \\
\hline \multicolumn{11}{|c|}{ Calculations } \\
\hline${ }^{l} g_{c}^{1}$ & & 0.118 & 0.099 & 0.101 & 0.172 & 0.114 & 0.180 & 0.110 & 0.112 & 0.171 \\
\hline${ }^{r} g_{c}^{1}$ & & 0.271 & 0.154 & 0.130 & 0.576 & 0.236 & 0.330 & 0.356 & 0.491 & 0.422 \\
\hline$\sigma_{c}^{1}$ & & 0.042 & 0.026 & 0.014 & 0.182 & 0.058 & 0.071 & 0.116 & 0.124 & 0.113 \\
\hline$\eta_{c}^{1}$ & & 0.198 & 0.590 & 0.604 & 1.911 & 1.604 & 1.604 & 1.604 & 0.259 & 0.523 \\
\hline \multicolumn{11}{|c|}{ Triangular fuzzy numbers } \\
\hline$l_{c}^{1}$ & & 0.114 & 0.065 & 0.082 & 0.000 & 0.000 & 0.023 & 0.000 & 0.077 & 0.045 \\
\hline$m_{c}^{1}$ & & 0.143 & 0.119 & 0.112 & 0.437 & 0.190 & 0.272 & 0.262 & 0.190 & 0.257 \\
\hline$r_{c}^{1}$ & & 0.289 & 0.211 & 0.161 & 0.779 & 0.316 & 0.428 & 0.516 & 0.628 & 0.663 \\
\hline
\end{tabular}

Note: The fuzzy numbers shown in bold were truncated using Eq. (18).

Table 11. The left values of the scores of each PDS option.

\begin{tabular}{cccccccccccc}
\hline & $\boldsymbol{\alpha}_{\mathbf{0 . 0}}^{l}$ & $\boldsymbol{\alpha}_{\mathbf{0 . 1}}^{l}$ & $\boldsymbol{\alpha}_{\mathbf{0 . 2}}^{l}$ & $\boldsymbol{\alpha}_{\mathbf{0 . 3}}^{l}$ & $\boldsymbol{\alpha}_{\mathbf{0 . 4}}^{l}$ & $\boldsymbol{\alpha}_{\mathbf{0 . 5}}^{l}$ & $\boldsymbol{\alpha}_{\mathbf{0 . 6}}^{l}$ & $\boldsymbol{\alpha}_{\mathbf{0 . 7}}^{l}$ & $\boldsymbol{\alpha}_{\mathbf{0 . 8}}^{l}$ & $\boldsymbol{\alpha}_{\mathbf{0 . 9}}^{l}$ & $\boldsymbol{\alpha}_{\mathbf{1 . 0}}^{l \& \boldsymbol{r}}$ \\
\hline CM-A & 0.004 & 0.008 & 0.014 & 0.021 & 0.039 & 0.064 & 0.092 & 0.124 & 0.158 & 0.195 & 0.236 \\
DB & 0.010 & 0.019 & 0.031 & 0.046 & 0.065 & 0.089 & 0.116 & 0.146 & 0.179 & 0.215 & 0.253 \\
DBB & 0.037 & 0.039 & 0.043 & 0.052 & 0.067 & 0.086 & 0.110 & 0.138 & 0.171 & 0.207 & 0.248 \\
CM-R & 0.009 & 0.020 & 0.032 & 0.046 & 0.063 & 0.087 & 0.115 & 0.146 & 0.181 & 0.220 & 0.263 \\
\hline
\end{tabular}

Table 12. The right values of the scores of each PDS option.

\begin{tabular}{cccccccccccc}
\hline & $\boldsymbol{\alpha}_{\mathbf{1 . 0}}^{\text {l\&r}}$ & $\boldsymbol{\alpha}_{\mathbf{0 . 9}}^{r}$ & $\boldsymbol{\alpha}_{\mathbf{0 . 8}}^{r}$ & $\boldsymbol{\alpha}_{\mathbf{0 . 7}}^{r}$ & $\boldsymbol{\alpha}_{\mathbf{0 . 6}}^{r}$ & $\boldsymbol{\alpha}_{\mathbf{0 . 5}}^{r}$ & $\boldsymbol{\alpha}_{\mathbf{0 . 4}}^{r}$ & $\boldsymbol{\alpha}_{\mathbf{0 . 3}}^{r}$ & $\boldsymbol{\alpha}_{\mathbf{0 . 2}}^{r}$ & $\boldsymbol{\alpha}_{\mathbf{0 . 1}}^{r}$ & $\boldsymbol{\alpha}_{\mathbf{0 . 0}}^{r}$ \\
\hline CM-A & 0.236 & 0.284 & 0.337 & 0.394 & 0.457 & 0.525 & 0.598 & 0.675 & 0.758 & 0.845 & 0.938 \\
DB & 0.253 & 0.309 & 0.369 & 0.435 & 0.505 & 0.580 & 0.660 & 0.744 & 0.834 & 0.928 & $\mathbf{1 . 0 0 0}$ \\
DBB & 0.248 & 0.295 & 0.347 & 0.402 & 0.462 & 0.526 & 0.594 & 0.667 & 0.743 & 0.824 & 0.909 \\
CM-R & 0.263 & 0.323 & 0.389 & 0.461 & 0.538 & 0.622 & 0.711 & 0.806 & 0.907 & $\mathbf{1 . 0 0 0}$ & $\mathbf{1 . 0 0 0}$ \\
\hline
\end{tabular}

Table 13. Final ranking of different PDS options.

\begin{tabular}{lccc}
\hline & Project delivery system & $\begin{array}{c}\text { Final score } \\
\text { (defuzzified value) }\end{array}$ & Rank \\
\hline Option 1 & CM-A (Construction Management-Agency) & 0.3541 & 4 \\
Option 2 & DB (Design-Build) & 0.3958 & 2 \\
Option 3 & DBB (Design-Bid-Build) & 0.3619 & 3 \\
Option 4 & CM-R (Construction Management-at Risk) & 0.4195 & 1 \\
\hline
\end{tabular}

different PDS options has been calculated for different values of $\beta$. As shown in Table 14, the CM-R (Construction Management-at Risk) is the best ranked alternative and DB (Design-Build) receives the second rank for different values of $\beta$. However, the ranks of CM-A (Construction Management-Agency) and DBB
(Design-Bid-Build) have changed as the values of $\beta$ increased. In the case the value of $\beta$ is equal to 0.0 or 0.3, CM-agency and DBB will have the third and fourth ranks, respectively; While, in the case the value of $\beta$ is selected $0.5,0.7$, or 1.0 , the CM-A and DBB will have the fourth and third ranks, respectively. 
Table 14. Final ranking of different PDS options for different values of $\beta$.

\begin{tabular}{|c|c|c|c|c|c|c|c|c|c|c|c|c|}
\hline \multirow{2}{*}{$\begin{array}{c}\text { Project delivery } \\
\text { systems }\end{array}$} & \multicolumn{2}{|c|}{ No weight } & \multicolumn{2}{|c|}{$\beta=0.0$} & \multicolumn{2}{|c|}{$\beta=0.3$} & \multicolumn{2}{|c|}{$\beta=0.5$} & \multicolumn{2}{|c|}{$\boldsymbol{\beta}=0.7$} & \multicolumn{2}{|c|}{$\beta=1.0$} \\
\hline & Score & Rank & Score & Rank & Score & Rank & Score & Rank & Score & Rank & Score & Rank \\
\hline $\begin{array}{l}\text { CM-A (Construction } \\
\text { Management-Agency) }\end{array}$ & 0.3784 & 4 & 0.3487 & 3 & 0.3594 & 3 & 0.3541 & 4 & 0.3584 & 4 & 0.3637 & 4 \\
\hline DB (Design-Build) & 0.3929 & 2 & 0.3759 & 2 & 0.3842 & 2 & 0.3958 & 2 & 0.3988 & 2 & 0.4026 & 2 \\
\hline DBB (Design-Bid-Build) & 0.3924 & 3 & 0.3460 & 4 & 0.3537 & 4 & 0.3619 & 3 & 0.3670 & 3 & 0.3792 & 3 \\
\hline $\begin{array}{l}\text { CM-R (Construction } \\
\text { Management-at Risk) }\end{array}$ & 0.4243 & 1 & 0.4130 & 1 & 0.4192 & 1 & 0.4195 & 1 & 0.4191 & 1 & 0.4183 & 1 \\
\hline
\end{tabular}

Table 15. Final ranking of different PDS options using WAA method.

\begin{tabular}{|c|c|c|c|c|c|c|c|c|c|c|c|c|}
\hline \multirow{2}{*}{$\begin{array}{c}\text { Project delivery } \\
\text { systems }\end{array}$} & \multicolumn{2}{|c|}{ No weight } & \multicolumn{2}{|c|}{$\beta=0.0$} & \multicolumn{2}{|c|}{$\beta=0.3$} & \multicolumn{2}{|c|}{$\beta=0.5$} & \multicolumn{2}{|c|}{$\beta=0.7$} & \multicolumn{2}{|c|}{$\beta=1.0$} \\
\hline & Score & Rank & Score & Rank & Score & Rank & Score & Rank & Score & Rank & Score & Rank \\
\hline $\begin{array}{l}\text { CM-A (Construction } \\
\text { Management-Agency) }\end{array}$ & 0.2311 & 4 & 0.2276 & 4 & 0.2300 & 4 & 0.2316 & 4 & 0.2333 & 4 & 0.2357 & 4 \\
\hline DB (Design-Build) & 0.2649 & 1 & 0.2738 & 1 & 0.2702 & 1 & 0.2678 & 1 & 0.2655 & 1 & 0.2619 & 1 \\
\hline DBB (Design-Bid-Build) & 0.2482 & 3 & 0.2436 & 3 & 0.2444 & 3 & 0.2450 & 3 & 0.2456 & 3 & 0.2465 & 3 \\
\hline $\begin{array}{l}\text { CM-R (Construction } \\
\text { Management-at Risk) }\end{array}$ & 0.2576 & 2 & 0.2564 & 2 & 0.2570 & 2 & 0.2573 & 2 & 0.2577 & 2 & 0.2582 & 2 \\
\hline
\end{tabular}

\subsection{Step 5: Final ranking}

Considering the abovementioned calculations, it is finally concluded that CM-R (Construction Management-at Risk) is selected as the best PDS option for the execution of this real-world dam and hydro power plant project.

\section{Comparison of FMCGDM with WAA method}

Aggregation is one of the most important steps in the group decision making process. In this step, the opinions of different DMs are aggregated to rank the PDS options. In this section, the results achieved from FMCGDM are compared to those of the widely used WAA (Weighted Arithmetic Averaging) method. The reason is that in this research, the input data (i.e. criteria weights and scores) are crisp numbers, and WAA is one of the basic methods that can be used in situations where aggregating arguments are exact numeric values [31].

For this purpose, the scores of different PDS options are calculated using WAA method for five different values of $\beta$ as $0.0,0.3,0.5,0.7$, and 1.0 . Table 15 shows the resulted scores and rankings of PDS options. As shown, the final ranking of PDS options is not dependent on the values of $\beta$. Using WAA method, the second PDS alternative, i.e. DB, is selected as the best PDS option. CM-R, DBB, and CM-A achieved the second, third, and fourth ranks, respectively.

Comparing the results obtained from FMCGDM method (Table 14) and those of the WAA method (Table 15), it is revealed that the selected final PDS option is different. Using FMCGDM method, CM-R is selected as the best PDS option. In the case of using WAA method, however, DB is selected as the best option. The reason is that the uncertainties affecting the PDS selection problem are not taken into account in WAA method. In Figure 4, the final scores of different PDS options in WAA versus FMCGDM method are compared for different values of $\beta$.

\section{Conclusions and remarks}

An integrated Fuzzy-AHP multi-criteria group decision making (FMCGDM) approach was presented to select the best alternative Project Delivery System (PDS). The proposed approach resolved two major shortcomings of the previous works. First, the proposed approach can select the best PDS option based on the opinions of a heterogeneous group of experts. For the purpose of dealing with a heterogeneous group of experts, the relative weights of DMs were determined using a new method which accounted for the diversity of opinions given by a group of experts as well as the group manager opinion regarding the importance of different DMs. Second, the crisp values of criteria 

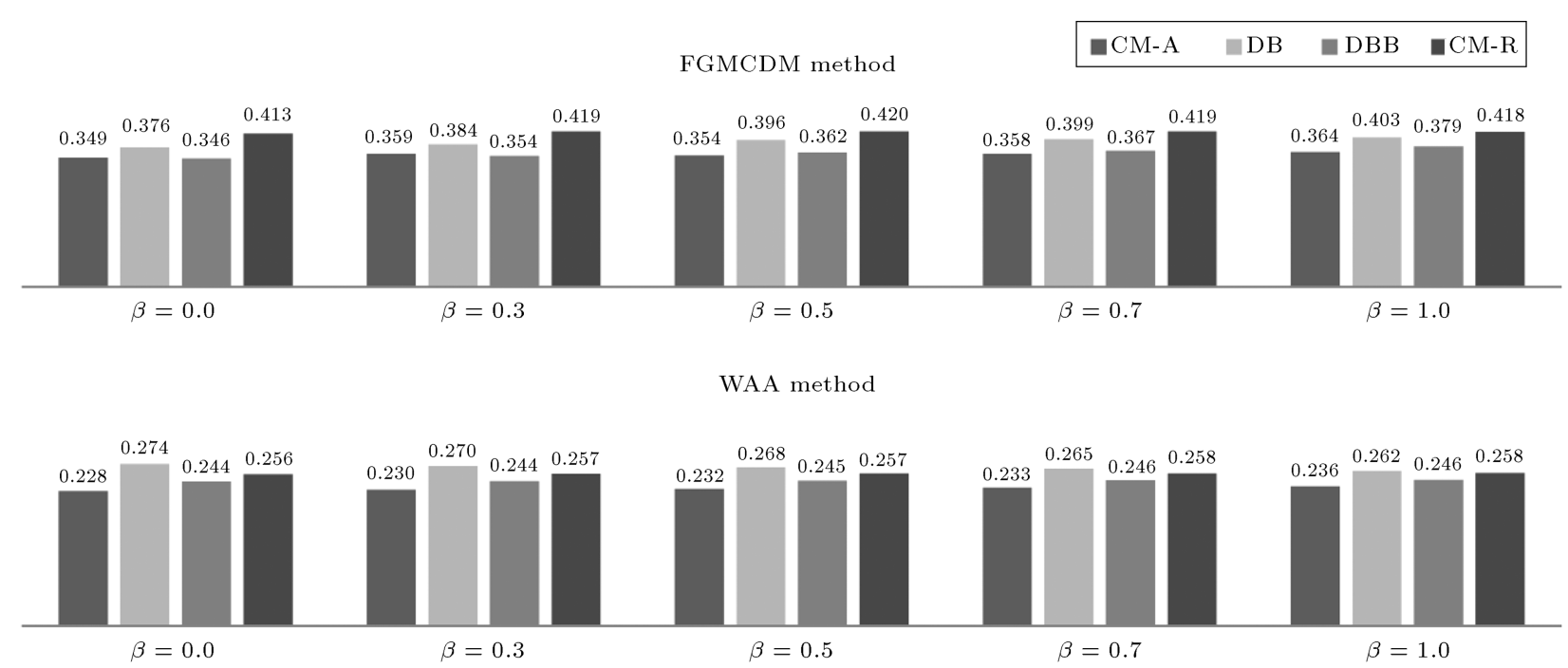

Figure 4. Comparing the final scores of different PDS options in WAA versus FGMCDM for different values of $\beta$.

weights and scores derived from AHP were aggregated and converted to a fuzzy number. The fuzzy numbers produced by the proposed method have the ability to represent the central tendency and divergence of the grading results. In order to determine the final fuzzy score of each PDS option, the fuzzy number of relative weights of criteria and their assigned scores were multiplied and summed up for each PDS option using Zadeh's extension principle and performing interval arithmetic at discrete $\alpha$-cuts. The resulted fuzzy scores of different PDS options were defuzzified and the best PDS option was selected. Sensitivity analysis was conducted to determine how the achieved final results were dependent on the variations in the value of $\beta$ as the importance of the opinion of group manager over the opinions of other group members. The proposed FMCGDM method was implemented on a real-world dam and hydro power plant project to determine the best alternative PDS. The CM$\mathrm{R}$ (Construction Management-at Risk) was selected as the best PDS option for the execution of this project.

The results of the proposed FMCGDM method were compared with those of the widely used WAA to reveal the capabilities of the proposed method. Comparing the results achieved from FMCGDM method with those of the WAA method revealed that the selected final PDS option was different since the uncertainties affecting the PDS selection problem as well as the relative weights of decision makers were not accounted in the WAA method. Although more sample projects are needed to validate the outputs of the model, accounting for the relative weights of decision makers and uncertainties affecting the PDS selection by the proposed FMCGDM approach may provide a powerful tool for project delivery system selection problem.

\section{References}

1. De Miranda Mota, C.M., De Almeida, A.T. and Alencar, L.H. "A multiple-criteria decision model for assigning priorities to activities in project management", International Journal of Project Management, 27, pp. 175-181 (2009).

2. Yeo, K.T. and Ning, J.H. "Integrating supply chain and critical chain concepts in engineer-procureconstruct (EPC) projects", International Journal of Project Management, 20, pp. 253-262 (2002).

3. Chen. Y.Q., Liu. J.Y., Li, B. and Lin, B. "Project delivery system selection of construction projects in China", Expert Systems with Applications, 38(5), pp. 5456-5462 (2011).

4. Lahdenperä, P. "Project delivery systems in Finnish new building construction - a review of the last quarter century", Procedia Economics and Finance, 21, pp. 162-169 (2015).

5. Nasirzadeh, F., Naderpajouh, N., Afshar, A. and Etesami, A., Fuzzy Approach to Project Delivery System Selection, Center of Infrastructure Systems, Nanyang Technological University, 3rd International ICCPMICCEM Conference (2007).

6. Gordon, C.M. "Choosing appropriate construction contracting method", Journal of Construction Engineering and Management, 120(1), pp. 196-209 (1994).

7. Alhazmi, T. and McCaffer, R. "Project procurement system selection model", Journal of Construction Engineering and Management, 126(3), pp. 176-184 (2000).

8. Cheung, S.O., Lam, T.I., Wan, Y.W. and Lam, K.C. "Improving objectivity in procurement selection", Journal of Management in Engineering, 17(3), pp. 132-139 (2001).

9. Mahdi, I.M. and Alreshadi, K. "Decision support system for selecting the proper project delivery method 
using analytical hierarchy process (AHP)", International Journal of Project Management, 23, pp. 564-572 (2005).

10. Oyetunji, A. and Anderson, S.D. "Relative effectiveness of project delivery and contract strategies", Journal of Construction Engineering and Management, 132(1), pp. 3-13 (2006).

11. Mafakheri, F., Dai, L., Slezak, D. and Nasiri, F. "Project delivery system selection under uncertainty: Multi-criteria multi-level decision aid model", Journal of Management in Engineering, 23(4), pp. 200-206 (2007).

12. Mostafavi, A. and Karamouz, M. "Selecting appropriate project delivery system: fuzzy approach with risk analysis", Journal of Construction Engineering and Management, 136(8), pp. 923-930 (2010).

13. Zadeh, L.A. "Fuzzy sets", Information and Control, 8, pp. 338-353 (1965).

14. Saaty, T.L. "A scaling method for priorities in hierarchical structures", Journal of Mathematical Psychology, 15(3), pp. 234-281 (1977).

15. Sipahi, S. and Timor, M. "The analytic hierarchy process and analytic network process: An overview of applications", Management Decision, 48(5), pp. 775808 (2010).

16. Bertolini, M., Braglia, M. and Carmignani, G. "Application of the AHP methodology in making a proposal for a public work contract", International Journal of Project Management, 24, pp. 422-430 (2006).

17. Saaty, T.L., Fundamentals of Decision Making and Priority Theory with the Analytic Hierarchy Process, RWS, Pittsburgh (2000).

18. Vargas, L.G. "An overview of the analytic hierarchy process and its application", European Journal of Operational Research, 48(1), pp. 2-8 (1990).

19. Saaty, T.L., Decision Making for Leaders, RWS, Pittsburgh (1995).

20. Zimmermann, H., Fuzzy Set Theory and Its Applications, 3rd Edition, Kluwer Academic Publisher (1996).

21. Seo, S., Aramaki, T., Hwang, Y. and Hanaki, K. "Fuzzy decision-making tool for environmental sustainable buildings", Journal of Construction Engineering and Management, 130(3), pp. 415-423 (2004).

22. Al-Subhi Al-Harbi, K.M. "Application of the AHP in project management", International Journal of Project Management, 19, pp. 19-27 (2001).

23. Azadi, H., Shahvali, M., Berg, J. and Faghih, N. "Sustainable rangeland management using a multifuzzy model: How to deal with heterogeneous experts' knowledge", Journal of Environmental Management, 83, pp. 236-249 (2007).

24. Cheng, C.B. "Group opinion aggregation based on a grading process: A method for constructing triangular fuzzy numbers", Computer and Mathematics with Application, 48, pp. 1619-1632 (2004).
25. Dorsey, R.W. "Project delivery systems for building construction", Associated General Contractors of America, Washington D.C. (1997).

26. PB Network, "Alternative project delivery system", Technical Report, 46(1), Howard Press, Roselle, USA (2000).

27. Nieto-Morote, A. and Ruz-Vila, F. "A fuzzy approach to construction project risk assessment", International Journal of Project Management, 29, pp. 220-231 (2011).

28. Rouhparvar, M., Zadeh, H.M. and Nasirzadeh, F. "Quantitative risk allocation in construction projects: A fuzz-bargaining game approach", IJIEPR, 25(2), pp. 83-94 (2014).

29. Chu, T.C., Huang, K.S. and Chang, T.M. "COA defuzzification method for evaluating Cpk under fuzzy environments", Journal of Discrete Mathematical Sciences and Cryptography, 7, pp. 271-280 (2004).

30. Nasirzadeh, F., Rouhparvar, M., Zadeh, H.M. and Rezaei M. "Integrating system dynamics and fuzzy bargaining for quantitative risk allocation in construction projects", Scientia Iranica, Transactions A, 22(3), pp. 668-678 (2015).

31. Xu, Z.S. and Da, Q.L. "An overview of operators for aggregating information", International Journal of Intelligent Systems, 18, pp. 953-969 (2003).

32. Nasirzadeh, F., Khanzadi, M., Afshar, A. and Howick, S. "Modeling quality management in construction projects", International Journal of Civil Engineering, 11(1), pp. 14-22 (2013).

\section{Biographies}

Mostafa Khanzadi has a PhD degree in Civil Engineering. He is currently an Assistant Professor in the Department of Civil Engineering at Iran University of Science and Technology. His main proficiency is in the area of project management, contract management, and risk management.

Farnad Nasirzadeh has a PhD degree in Construction Engineering and Management. He is currently an Associate Professor in the Department of Civil Engineering at Payame Noor University (PNU). His main proficiency is in the area of project risk management and modeling and simulation of construction projects.

Seyyed Mohammad Hossein Hassani has an MSc degree in Construction Engineering and management. His main proficiency is in the area of contract management and project management.

Negar Nejad Mohtashemi has an MSc degree in Construction Engineering and Management. His main proficiency is in the area of project management. 